\title{
The Pre-Dawn Language of Dawn of Dreams
}

\section{Sudhakar Marathé}

There are two kinds of translations, literary translations and business, other kinds of content related translations, such as telling someone what directions appear on a packet of instant noodles. There may be a few instances in which the types seem to merge. But by and large, given access to the original, one can make out the difference beyond quibble. The second type is done only in classrooms and during an introduction to a piece of writing or in business contexts where information matters and nothing else does, for someone who does not know the original language. That is more or less literal translation, which does not have to satisfy any rigorous linguistic criteria regarding acceptability in the target language. Communicating the gist or a particular twist of the original is the motivation for such translation. The first kind of translation comprises rendering a whole text with significant human or experiential content into another language so as to become a genuine counterpart of the original in the target language and literature. There is no doubt at all that Dawn of Dreams aspires to become a translation of the first type. In fact it appears that while the original Urdu novel adopts a simple and at times even literal style of narration, the "literalness" of Dawn of Dreams is minimal and unintentional, clearly arrived at from inability to exploit or employ idiomatic English.

Although its original was written in Urdu, Dawn of Dreams expects to be read at least as a pseudo-novel in English. Therefore one is justified in expecting it to become more than minimally readable in English, never mind the occasional effort the translator may have made to retain the flavour of the original. Whatever one may say about conveying the "flavour of the original language", there is an essential expectation from literary translation: that by and large it will conform to the idiom of the target language-literature. Here idiom means the 'grammar' or 
patterns of acceptability in English at every level: punctuation, speech, vocabulary, phrasing, sentence construction, elisions and even metaphor and other literary devices. I am afraid Dawn of Dreams fails to fulfil this expectation utterly. Consequently, its literary achievement and integrity as a human text to be read in English are highly doubtful. Needless to say, in innumerable places the language of translation not only lets English down but it also lets down the undemanding Urdu of the original.

The original novel is probably a worthwhile document in historical, cultural and political terms, and that as a document the translated version may supply an intellectual counterpart of that relevance. However, if one merely wishes to convey information about characters and themes, why bother to write a novelistic translation when an article can convey the necessary "information"? In my paper I shall support my claim-that Dawn of Dreams fails as a translation-by means of a thorough examination of many aspects of the language of Dawn of Dreams. For this purpose, I shall examine the first $\mathbf{1 6}$ or $\mathbf{1 7}$ perfectly representative pages of the translated text in as much detail as is necessary. The rest perpetuates the same kind of shortcomings and flaws as the portion I examine. However, first let us identify the translator's task in translating the language of the original into the target text.

The first thing to appreciate about any novel as an object of perusal and an object of translation is that it constitutes an extended series of narrated incidents that somehow communicate the drama of experience: that comprises dramatic description of time, place, person, season, etc., dramatic dialogue and dramatic action. The more emphatic or charged the drama in the original, the more difficult it is to translate it in measured language. But even in the most linear-sounding narrative, nothing is either merely simple or straightforward. In the most innocent looking narrative at some level everything moves back and forth and laterally, quickly or slowly, almost ceaselessly, and the language is meant to convey human experience far beyond words. The 
translator must notice, understand, appreciate and render in the target novel all the paths and techniques that perform the work of narration in the original text. Translation of a novel can fail because its narrative is too un-dramatic to hold readers' interest, because it fails to communicate the flavour of the felt experiences of characters. So a translator's essential task is to render what I have called the dramatic or felt quality of the original. I must confess that I have not read in many years a narrative as un-dramatic as Dawn of Dreams.

A novelist needs to strive to the utmost of his ability to overcome this constraint so that he can use the advantages of narration and also milk the maximum value of dramatisation. Add to this the fundamental, essential and historically primary motivation for any self-conscious narration: that it wishes to dramatise something so as to capture and hold the audience's interest. Here is a classic explanation of the phenomenon of narration, the human voice, whether spoken or written. I quote a passage from a "Preface" of Rudyard Kipling. In it an English writer of short stories has become friendly with Gobind, an ancient Sadhu who had been a well known story teller in his time. He asks Gobind's advice about narration. Gobind spells out, typically via a story, the art and craft a narrator (and by obvious implication a translator) must manifest:

'A tale that is told is a true tale as long as the telling lasts. And you know how Bilas Khan, that was the prince of taletellers, said to one who mocked him in the great rest-house on the Jhelum road: "Go on, my brother, and finish that I have begun," and he who mocked took up the tale, but having neither voice nor manner for the task came to a standstill, and the pilgrims at supper made him eat abuse and stick half the night.'1

The unavoidable implication is serious: the translator must experience as much of the overt or hidden drama of the original novel as possible, winkle out and identify the techniques used to create it and render them in his translated version of it. The 
techniques include ways of making the narration sound out of the ordinary or true to the ordinary in especially interesting ways and of making the dialogue sound natural to the circumstances and characters involved in it. The drama of a narrative lies in part in the incident or action-but written language is a mere indication of the full language, most of which lies in the heard narrative, not the flat and lifeless black and white narrative. So the translator must also discover or create means or techniques of doing so that would be considered appropriate and idiomatic in the target language in its written as well as heard shape. A translation that aspires to literary quality cannot merely be a make-shift, rough or lackadaisical representation of the original dramatic material and techniques.

T. S. Eliot said in an early twentieth-century essay on vers libre or free verse 2 that such verse is not literally free at all and that indeed in art it is impossible to achieve freedom without first being subjected to some essential constraint. Indeed one might even claim that the urge to create arises from a desire to confront the challenges of constraints. The chief constraint on translation is that it must reproduce, in a form recognizable and acceptable in the target language, as much of the original artefact as possible and not merely the gist or surface sense of the original. In the present instance the translation fails because the translator has simply ignored these attempts or is incapable of producing the requisite expression in English. This expectation relates to every level and aspect of language no matter how insignificant it may seem. Dawn of Dreams flouts this expectation at every step.

Let us begin with the most innocent looking and sounding subject of punctuation. The sound pattern of every language is unique. At the same time, its unique writing system cannot even remotely represent its sound system. The only means by which, when transcribed, a language may barely hint at the sound and interpretation of grammatical structures beyond words is its punctuation. Just as importantly, while for sheer convenience and because of colonial and other influences most languages 
today use the same punctuation signs, their implication for how the narrative sounds is different in each language. Our translator seems to have been unaware of both these facts: that punctuation is a poor yet crucial vestige of spoken language, and that it follows different rules and sets up different expectations in English from Urdu. Consequently, Dawn of Dreams is littered with punctuation errors, chiefly errors of omission of crucial punctuation. Consequently, the English version is poor and uninteresting. Here are some examples of this problem with Dawn of Dreams:

An apparently trivial instance comes on page 3, "there has been destruction on the other side too; though you may not feel its pain." But sentences beginning with though are dependent clauses and cannot be connected to main clauses with the semi-terminal sign ;. Look at the following sentence on page 12: "Sarkar you know, don't you huzoor?" What sense is it supposed to make? Is it to be read as "Sarkar, you know", or without the comma, meaning "you know the Sarkar"? And one needs a comma in "don't you huzoor?" to help read the sentence, as in "don't you, huzoor?" On the same page you have, "Employers never glanced at it let alone sat on it". It ought to be, "Employers never glanced at it, let alone sat on it". Similarly, on the same page you have "Let it be Ghaffar Miyan don't bother", which ought to be "Let it be, Ghaffar Miyan, don't bother". On page 13 you have "But what about us Ragho Bhai?" which ought to be "But what about us, Ragho Bhai?" At the beginning of page $\mathbf{1 4}$ you have "Gumastaji was proud of his mane of white hair which incidentally hadn't been bleached by the sun". Just as one needs commas to help separate items to allow one to use the right intonation in all the previous examples, so does one need two commas here to set the parenthesis apart from the rest of the sentence, both for its understanding and for its utterance, like this: "Gumastaji was proud of his mane of white hair, which, incidentally, hadn't been bleached by the sun". The original sentence indeed makes no sense at all, while clearly the intended 
sense is that the hair was not merely bleached by strong sun but was a clear mark of seniority.

A similar problem with a parenthesis comes further down page 14: "Anwar cast a cursory look at * faces before him and in his own way, comprehended what was writ large upon them." This ought to be "Anwar cast a cursory look at the faces before him and, in his own way, comprehended what was writ large upon them." When a parenthesis occurs in the middle of a sentence, it needs punctuation on both sides to mark it. Further, in the middle of page $\mathbf{1 5}$ you have Aliya's admonition that ends with this: "... what will happen now? But as if you care?" The context makes it abundantly clear that the last tag is not a question but an exclamation and ought to be written as follows: "...what will happen now? But as if you care!" Finally, I shall cite just one more quite extreme example on page 15: "He alone is our provider, what is this zamindari, God forbid, is that our God?" In fact the sentence makes no sense mainly because its punctuation is haywire and a wrongly chosen pronoun also helps increase the confusion. The sentence can at best be printed as follows: "He alone is our provider. What is this zamindari? God forbid! It is not our God!" I shall not flog the matter further but instances of confusing punctuation or confusing absence of punctuation mar the whole text from beginning to end, defying the expectations natural to the English language, instead of fulfilling them so that the reader can make quick and rounded sense of what he reads. The text is most carelessly and also erroneously punctuated.

Next let us look at what for most people constitutes language, vocabulary. Unfortunately, there are three fundamental problems with vocabulary also that virtually no one seems quite aware of; certainly, teachers of English by and large remain ignorant of them and so do many indigenous translators: first, that no dictionary meaning is ever really useful; words only acquire meaning only when they are used in specific contexts; 
until then words only have potential meanings. In a given context one must pick the word with the most appropriate sense. Second, even such applicable senses have stylistic restrictions on them, can be used only in certain conditions and not in others; so merely because a word seems to have the meaning one is seeking one cannot proceed to use it without considering contextual and other restrictions on usage. And third, even when a word with an appropriate sounding sense is chosen, one must check very thoroughly indeed whether it fits idiomatic expectations or whether an alternative must be sought for use in given conditions. Let is consider some examples of problems with vocabulary and phrasing in Dawn of Dreams.

The very opening of the novel is inauspicious. The original reads like this: ghadi ki tik tik udasi ka khamosh eilan kar rahi thi. But the English translation reads like this: "the ticking of the clock was like a mute declaration of gloom."The original khamosh eilan means unspoken declaration, or that it happened when no one was saying a word, while the word mute is merely a crude contradiction in terms: "ticking" is most definitely a sound and cannot be "mute". The same page presents us with "The question concerns the rest of your life". The original does not say that. It says, "abhi apki sari umra padi hai", which means "you still have the rest of your life before you". Again, the translation says at the beginning of page 2: "Do you imagine Dulhabhai will listen to us?" But the original does not include the notion of imagining: "bhala hum logonki bat dulhabhai sunenge", which is a rhetorical utterance, not a question at all: "But dulhabhai isn't likely to listen to us, is he!" On the same page the translation says, "Such opportunities don't come everyday." But in English everyday is not an adverb of time at all, it is an adjective that means daily; for instance, commuting to work is an everyday experience for many urban Indians; the expression ought to be every day. Moreover, everyday is spoken with stress on the first syllable; but every day is spoken with stress on the second syllable. And it is such hints, which the translation 
carelessly misses, that communicate the intended meaning in any language. On page 1 the translation says: "His people and relatives have property worth lakhs." But the original does not say people, it says "gharwale", so the translation ought to have said, "His family, his relations have property worth lakhs." Just at the end of page 1 the translation says, "Today you are alone", but the original says "aj ap tanha ho", and I believe that here "tanha" cannot be rendered as "alone" (after all, she does have a husband) but as childless. Further, in English it will sound crude to say "today you are childless"; so the idiomatic choice is, "today you have no children"; or even better, "you have no children yet".

At the beginning of page $\mathbf{2}$ we have "Aliya khatun used a hand-fan to make him feel cooler". That is not English at all. Nor was he cool already to become "cooler"! Of course one fans someone to cool them. So in English one need only say, "Aliya khatun fanned him with a hand-fan". Next, in the same paragraph on page $\mathbf{2}$ we have "A servant brought a glass of water, which he drank thirstily. He asked for more. After two glasses, he smiled...". That is not idiomatic either. It ought to be "after the second glass, he smiled". On page $\mathbf{3}$ of the translation Anwar Ahmad says, "No one will blame you now for not observing the customary procedure of saying 'good-bye."' No one will use the word procedure in such a context except a pompous Foreign Ministry bureaucrat. The idiomatic expression ought to be something like this: "You have only come here to say the usual / customary good-bye". Again, at the start of page 4 we have "Yes, these men are lucky fellows. They don't suffer from such weaknesses". Regardless of what it is in the original, this is not really idiomatic English. It ought to be rendered as "These chaps / men / fellows are lucky-they don't suffer from such weaknesses." Later on the same page the brothers invite Aliya Khatun and Anwar to visit them in Pakistan: "...you and Apa are welcome any time". Anwar replies: "Thank you indeed for this warm invitation". Never 
will in idiomatic conversation one say "this invitation". The expected expressions are: "Thank you for inviting us" or "Thank you for the warm invitation".

Chapter Two begins with leave-taking. Aliya Khatun's brothers are taking her leave. The translation says, "The tonga is here, our luggage has been stacked." This is pure dictionary violence. Of course one of the dictionary meanings of the original term is likely to be stacked. But dictionaries do not always tell you where not to use a word. In English no one will ever use the verb stacked in this context. One stacks things in a place to leave them there, for instance, the luggage has been loaded in the lorry and stacked properly: for instance, the boxes have been stacked at the back of the godown. Here the only sense is that their luggage has been put in the tonga or loaded on or into the tonga. On the same page we have "Don't cry, Apa, this was God's will that we should be thus separated." Because that we should be thus separated follows, the pronoun this will never be used in English. It has to be it: "it was God's will that", etc. At the beginning of page $\mathbf{7}$ we have "All this jewellery belongs to his mother. She gave it to me, but I haven't even touched it yet". This may be fine in Urdu-perhaps meine hath tak nahi lagaya hai-but not in English. Why would one want to "touch" jewellery? One either examines it or wears it. So it ought to be rendered as "I have never really looked at it" or "I have never even worn it yet". Then we have, "how many women are far-sighted enough to spot the darkness in the impending future?"The phrasing impending future is odd enough; the future is always impending; but one spots a specific object, such as an animal, a mosque dome, etc., in the distance. One cannot spot "darkness". It ought to be phrased as "to see the darkness". This is followed by "your tears will darken our path". How? Here, as elsewhere, the translator has done injustice to both the original and the target language. 
Chapter Three brings us this: "its beautiful décor, expensive furnishing, the expensive clothes...." The word furnishing is never used in the singular to mean the furniture and appointments of a place; it has to be in the plural form furnishings. Then, "but a subtle fading, pallor $><$ shadowed it all". First, what is the comma after fading doing here? Incidentally, the word pallor is normally used to describe a face. But in any case, it means paleness. How can paleness "shadow" anything? On page 9 once again we find everyday, where every day is required. Next comes "thank your lucky stars that Bade Sarkar didn't make you apologise". But the idiomatic expression is "thank your stars", because here "stars" means luck. Grammatical-idiomatic errors also occur in the translation. For instance, "Bade Sarkar's bread and butter have been snatched away". This error comes from unfamiliarity with how the idiom "bread and butter" sounds. It is not two separate items, bread and 'butter, but one, always uttered as one: ‘bread-and-butter. Therefore, the verb must be in the singular form, "bread and butter has been snatched away". Another instance on page 10 misuses the past tense of the verb "linger": "Come what may, the taste of his employer's salt still lingered in his mouth". The phrase "come what may" always and invariably relates to the future; so the verb ought to be "will linger". Next on the same page the verb should and the phrase by ourselves are erroneously used: "We should not quit by ourselves". The translator means, "we must not quit (our jobs)", let them dismiss us if they want to. Should does not carry the sense of must in such contexts; it is a verb much misused in India. The verb required here is must. And one always "quits a job oneself'; use of the word ourselves is poor. I shall only cite one more instance of misplaced vocabulary (from page 11): "Anwar Ahmad with his democratic ideas had hurt Patwariji's influence and authority". Influence and authority are not sentient or live, therefore they cannot be "hurt".

And then therearelargerlinguisticstructures thathavetheir 
uses but that also have their own "rules" of grammar and stylistic restrictions that must be respected. If one fails to do so one begs the question whether the work is indeed in the target language or in some sub-standard and unacceptable approximation of it. Dawn of Dreams exemplifies this phenomenon constantly as well. Let us consider several examples from the same early pages of Dawn of Dreams:

Once again, examples occur on every page. On page 10, for instance, we find "We are not paid salaries for six months at a stretch... and what a salary,' Patwariji said." The same sentence uses plural and singular forms of the same noun, without any excuse whatever. Besides, the expression is not a query but an exclamation; yet there is no exclamation mark after it. The concluding expression ought to have been, "and what salaries!" (Urdu text, page 16: "Chhe chhe maheene to hamlogoN ki tankhwaah ke ho jaate haiN, jabki tankhwaah hi kiya hai", Patwarji ne kahaa). Mixed metaphors also abound. Here is an instance from page 11: "This had disheartened the loyal worker. Nevertheless, the strength of his employer's salt still tied him securely to his master's post". In such contexts salt refers to a reason for a human being to be loyal to someone; but "tie to a post" refers to an animal; so the metaphor turns away from human loyalty to animal loyalty. Page 10 gives us "we people have some work ethics too". Here we is more than adequate in English, while we people is unidiomatic even if the original says hum log; in this context ethics is quite unacceptable; the plural term is used only to refer to the science of morality, the discipline of philosophy that studies morality; here the singular form is required, ethic; and a might suit the case better than some. (Urdu text, page 17: "jaanta hooN bhaai--------tumheiN to wah Aaj bulaa rahe haiN, merey peechhe to wah barsoN se paRe haiN, kiya kiya laalach naheeN diyaa, achhi tankhwaah, jaaedaad--------lekin bhai, hamlogoN ki naukri ke bhi kuchh osool hote haiN,----). The following sentence on page 11 mucks up a relative clause: "There was no trace of 
any special emotion on his face, which could be attributed to some new or vital information". This sentence in fact means the opposite of what it is intended to mean. The sense ought to be his face showed no expression that may be caused by "some new or vital information". But because of the intrusive comma, the sense that comes is: he showed no expression, and that was because of "some new or vital information"! (Urdu text, page 18: "unke chehre par door door tak kisi aham jaankaari ke aasaar naheeN the").

Sequences are often mucked up also. For instance, on page 13 we have this: Anwar Ahmad says, "'Ghaffar Miyan, that won't be of any help. He owes his identity to the zamindari system, not to any caste or community"' Then the narrator glosses this speech as follows: "Anwar Ahmad's comments left both employees speechless...." However, Anwar Ahmad has made only one comment. Sentences like the following confuse many ideas and figures: "Patwariji was trying to soften the sting Anwar Ahmad's slap had inadvertently planted on their cheeks just now". In fact, there has been no slap; slaps cannot be planted; how can a sting be "softened"? and why"inadvertently"? Tenses seem to cause the translator serious difficulty, too, especially expressions appropriate to tenses. Here is one instance: "Now the bread they are going to eat will not be made of simple wheat, it will be mixed with their sweat". In fact at this point in the narrative no one is "going to eat" anything at all. The reference is to an abstract condition in the future; so the phrasing ought to be, "the bread they eat now" or "the bread they eat hereafter". And what does "simple wheat" mean? Surely the sense requires "pure" or "unadulterated" used in an ironic sense? The translation denies its reader normally expected kinds of help in a variety of ways. Here is an instance from page 12: "That is how I, Anwar Ahmad will survive... what will happen to my children, how will I manage the household expenses? Then listen....". Once again, the initial sentence is unclear because a comma is missing after Ahmad; there has 
to be a comma after Ahmad because there is a comma after $\underline{\perp}$, and a noun phrase in apposition such as Anwar Ahmad that follows a comma must also end with a comma. Further, the two questions he utters are supposed to be those that bother Patwariji. And how will I needs to become how I will in the reported speech format used here. So the whole sentence ought to have run like this: "That is how I, Anwar Ahmad, will survive... you want to know what will happen to my children, how I will manage the household expenses? Then listen...."

One of the crucial things the translation fails to manage is conversational language; but unfortunately the original novel contains numerous dialogues. Therefore, this weakness becomes significant. Here are a couple of examples. On page 15: "Your ideas are beyond my comprehension; just tell me in simple language how we will run the house...." Beyond my comprehension clashes with "just tell me in simple language". Another sentence on page 16 goes, "why don't you just sit back and offer prayers and find money under the prayer mat. Why are you bothered about earning it through employment?" This is the language of a poorly written paper in sociology. How can one "sit back" and "offer prayers"? Next, mat ought to be followed by a question mark to end the question asked. And Why are you bothered about earning it through employment is simply monstrous! No ordinary person speaks like that in any language. Something like "Why bother with a job, then!" was required. On page 16 again we find this: "They were also zamindars. But they threw it away, they are happy, aren't they? They aren't being eaten up with worries like $><1$ am". There are four different problems here: first, there is no noun before it for which it can do duty as a pronoun; its use is simply poor syntax; then the comma after away is unidiomatic; there ought to be either a full stop there or a conjunction; also in such contexts worry is used in the singular in English (even if there are numerous causes of it), not in its plural form; and 
given the use of like, "I am" is quite unlikely to occur; me is what will occur in its place: They were also zamindars. But they threw all that away. They are happy, aren't they? They aren't being eaten up with worry like me.

In these and other extremely numerous locations the translation mixes up formality with informality, conversational language with pompous and inappropriately erudite language, poor punctuation with involved constructions, mixed metaphors, mixed registers of idiom, poor grammar with ambiguous construction, and so on and so forth. For instance on page 17 we find "But Anwar Ahmad's story of these repasts", where in fact the sense requires version in place of story; on the same page, Aliya Khatun is supposed to be saying, "Oh my God how will we go through all this? It's all very well to theorise but...". Now, not only is a crucial comma missing after "Oh my God" that a reader requires to realise her utterance; but "go through" is also an inappropriate choice; what was required was manage, or live through or survive. And who on earth would expect a person like Aliya Khatun to use the word "theorise"! As though this was not bad enough, this sentence is followed by this: "She took a deep breath and was probably muttering to herself because it was some time since Anwar Ahmad had gone to his room, to sleep". Once again, the comma before to sleep at the end is utterly uncalled for; but far more importantly, whatever can the word probably mean in this context? Anwar has left the room and there is no cause for uncertainty. Whether it is such inane choice of words or simply poverty of expression in usages such as "Sabir and Jabir were_experts at this game of giving loans", the language of Dawn of Dreams remains far from becoming English. In such constructions, for instance, experts is unacceptable, expert is idiomatically required; and far more importantly giving loans is a ridiculous way to refer to lending money or money lending!

In this paper I have not attempted to provide exhaustive examples for you from the entire text of Dawn of Dreams, although I could easily do that, because there simply is not enough time 
in a seminar presentation to do that. But I have not done so also because what I have brought before you is more than adequate to substantiate my point. Mistakes, infelicities, poor choices, inability to manage levels of language use in diction or style, simply mount throughout the narrative-its distance from the original and from whatever one might have expected as a reasonable version in English is a serious disappointment. As I indicated at the beginning, Khwabon ka savera provides plenty of food for serious thought. However, of course we can and need to analyse the events of the novel, the characters in it, its themes and their relationship to historical facts, its relevance to our social and political situation today and our future as a society. It is obviously worthwhile to do so. However, we may be able to do so even on the basis of a prosaic factual summary of all of these in an article. But to speak of Dawn of Dreams as even a moderately successful fictional version of Khwabon ka savera seems unfair to me. The translation has treated the original with scant respect-whatever the fictional achievement of the original may be.

\section{NOTES}

* Dr. Rizwana Moin, Reader, Department of Urdu, University of Hyderabad, kindly transliterated the first chapter of Khwabon ka savera into Devanagari for my edification.

All references to Dawn of Dreams cite the Chennai: Macmillan edition of 2001.

1. Life's Handicap, 1890.

2. "Reflections on vers libre". New Statesman, VIII, 204 (3 March 1917) 518-19. 